\title{
Renal insufficiency as a primary manifestation of sarcoidosis in a 13-year-old boy
}

\author{
Nasser Wael ${ }^{1}$, Safori Gassan ${ }^{2}$, Soboh Soboh ${ }^{2}$, Nakhoul Farid*3 \\ ${ }^{1}$ Pediatric Nephrology Unit, Baruch-Padeh Poriya Medical Center, Bar-Ilan University, Israel \\ ${ }^{2}$ Department of Internal Medicine, Baruch-Padeh Poriya Medical Center, Bar-Ilan University, Israel \\ ${ }^{3}$ Nephrology \& Hypertension Division, Baruch-Padeh Poriya Medical Center, The Faculty of Medicine in Galilee, Bar-Ilan \\ University, Israel
}

Received: October 9, 2016

DOI: $10.5430 /$ crim.v4n1p17
Accepted: November 27, $2016 \quad$ Online Published: November 30, 2016

URL: https://doi.org/10.5430/crim.v4n1p17

\begin{abstract}
Background: Childhood sarcoidosis is a multisystem granulomatous disorder of unknown etiology. The disease affects children aged 13-15 years, especially the lungs.

Objective: We describe a 13-year-old boy who presented to our pediatric nephrology division due to acute renal failure, cutaneous rash and anemia.

Methods: Percutaneous kidney biopsy was performed showing non-caseating granulomas with mononuclear infiltrates.

Results: Mantoux test and serology for Brucella were negative. Chest radiograph showed minimal, bilateral infiltrates. Renal ultrasound showed nephrocalcinosis. Pulmonary functions study demonstrated mild restrictive disturbance. Plasma creatinine was $1.8 \mathrm{mg} / \mathrm{dl}$ and calcium $12.3 \mathrm{mg} / \mathrm{dl}$.

Conclusion: In the current patient, renal insufficiency was discovered while exploring constitutional symptoms in a 13-year-old child. Early diagnosis and adapted treatment allows preserving renal function.
\end{abstract}

Key Words: Sarcoidosis, Granuloma, Renal failure, Mononuclear infiltrates, Vitamin D3

\section{INTRODUCTION}

Sarcoidosis is a multi-systemic disorder of unknown cause, pathologically characterized by the accumulation of inflammatory cells forming non-caseating granulomas. Lesions can be located in any organ but in more than $90 \%$ of patients, granulomas affect the lungs, the related lymph nodes, heart, eyes and liver. ${ }^{[1,2]}$ Sarcoidosis usually affects adults, who commonly present with Hilary lymphadenopathy, pulmonary infiltrates, uveitis, myocarditis, and erythema nodosum. ${ }^{[3,4]}$ The typical lesion is characterized by non-caseating granulomas. It is a rare disorder among children; estimated prevalence is 0.3 per 100,000 children per year. Prevalence in children is higher in the 13-15-year-old age group. It also varies with geographic location and racial distribution in the U.S. Blacks are affected about 15 times more commonly. ${ }^{[1-3]}$ Sarcoidosis in young children usually involves the skin with the typical erythema nodosum, joints with arthritis and the eyes with a severe uveitis. ${ }^{[2]}$ In older children, as in adults, the lungs, lymph nodes and eyes are the most frequently involved. Visceral sarcoidosis involving liver and spleen include visceromegaly, with multiple nodules hypodense on CT images.

\footnotetext{
*Correspondence: Nakhoul Farid, MD, Assisstant Professor; Email: fnakhoul@poria.health.gov.il; Address: Nephrology \& Hypertension Division, Baruch-Padeh Poriya Medical Center Lower Galilee, Faculty of Medicine in Galilee, Bar-Ilan University, Israel.
} 
Patients present to the physician with symptoms including fever, fatigue, malaise and weight loss. Acute kidney injury with renal failure occurs exceptionally in this disease. ${ }^{[3-7]}$ Symptoms are usually mild and can include cough, dyspnea and chest pain. Bilateral hilar lymphadenopathy is the most common early radiograph finding. Restrictive lung disease on pulmonary function tests can appear in 50\% of children. Skin manifestations, as erythema nodosum, present as an early symptom in $20 \%$ of patients. Skin involvement includes erythema nodosum and waxy pink nodular lesions. Ocular and visual symptoms such as intractable pain, blurry vision, photophobia, and redness are common in childhood sarcoidosis and can affect about $30 \%$ of children. Anterior uveitis and conjunctival granulomas are the most common manifestations. Cardiac manifestations can present with arrhythmias and heart failure. ${ }^{[9,10]}$

Main renal manifestations are hypercalcemia, hypercalciuria with nephrocalcinosis, nephrolithiasis which can cause acute kidney injury with renal failure. Acute interstitial nephritis with or without granulomas can also cause kidney injury. However, many patients with renal involvement can present with mild proteinuria and leukocyturia. ${ }^{[1]}$ Renal involvement in childhood sarcoidosis is rare, related to hypercalcemia and hypercalciurea in most cases. Disturbance in calcium balance occurs due to extrarenal excess production of 1,25-dihydroxyvitamin D by sarcoid macrophages and, subsequently, increased intestinal absorption of calcium. ${ }^{[12-14]}$ Biopsy will reveal infiltration of mononuclear cells to the interstitium leading to formation of non-caseating granulomas and chronic interstitial fibrosis. ${ }^{[4,5,15]}$

Although uncommon, renal involvement in childhood sarcoidosis is usually diagnosed relatively late and $40 \%$ of affected children will continue with insufficiency after treat- ment. The drug of choice in the treatment of severe renal and lung sarcoidosis is corticoisteroids. The dose of steroids (Prednisone) is $1 \mathrm{mg} / \mathrm{kg}$ Prednisone body weight for $1-2$ years. ${ }^{[17-19]}$

\section{CASE RePort}

A healthy 13-year-old boy was sent to our emergeny room in north Israel, with incidental findings of severe hypercalcemia and acute kidney injury (AKI), which was diagnosed by his primary care physician. Two months prior to his admission, he started complaining of weakness, loss of appetite and fatigue. Family history was significant for two uncles with chronic renal failure who are being treated by dialysis. On admission, the child was alert and responsive, with normal vital signs including blood pressure of $112 / 61 \mathrm{mmHg}$, heart rate was 80 , and he was afebrile. Physical examination with a clear chest, no peripheral lymphadenopathy, 1/6 systolic murmur and a purplish rash on left thigh. Laboratory data showed hemoglobin of $10.4 \mathrm{~g} / \mathrm{dl}$. The blood urea nitrogen (BUN) was $76 \mathrm{mg} / \mathrm{dl}$ and serum creatinine level was $1.81 \mathrm{mg} / \mathrm{dl}$ (Normal $=0.6-0.8 \mathrm{mg} / \mathrm{dl})$. Serum calcium level was $12.23 \mathrm{mg} / \mathrm{dl}$ (Normal $=8-10 \mathrm{mg} / \mathrm{dl}$ ), phosphor $=4 \mathrm{mg} / \mathrm{dl}$, other electrolytes were within normal range. Parathyroid (PTH) was $56 \mathrm{pg} / \mathrm{ml}(\mathrm{N}=11-60 \mathrm{pg} / \mathrm{ml})$, and thyroid stimulating hormone (TSH), TT3 and TT4 were normal. Urinary calcium/creatinine ratio was $3 \mathrm{mg} / \mathrm{mg}$. Chest radiograph showed minimal, bilateral, infiltrates (see Figure 1A). Chest CT was not performed due to his young age. Pulmonary functions study demonstrated mild restrictive disturbance. Oxygen saturation dropped from $99 \%$ to $89 \%$ during stress test. Kidney ultrasound showed mild hyperechogenicity, with nephrocalcinosis (see Figure 1B), but without nephrocalcinosis. Immunohistologic tests for brucella and tuberculosis were negative.
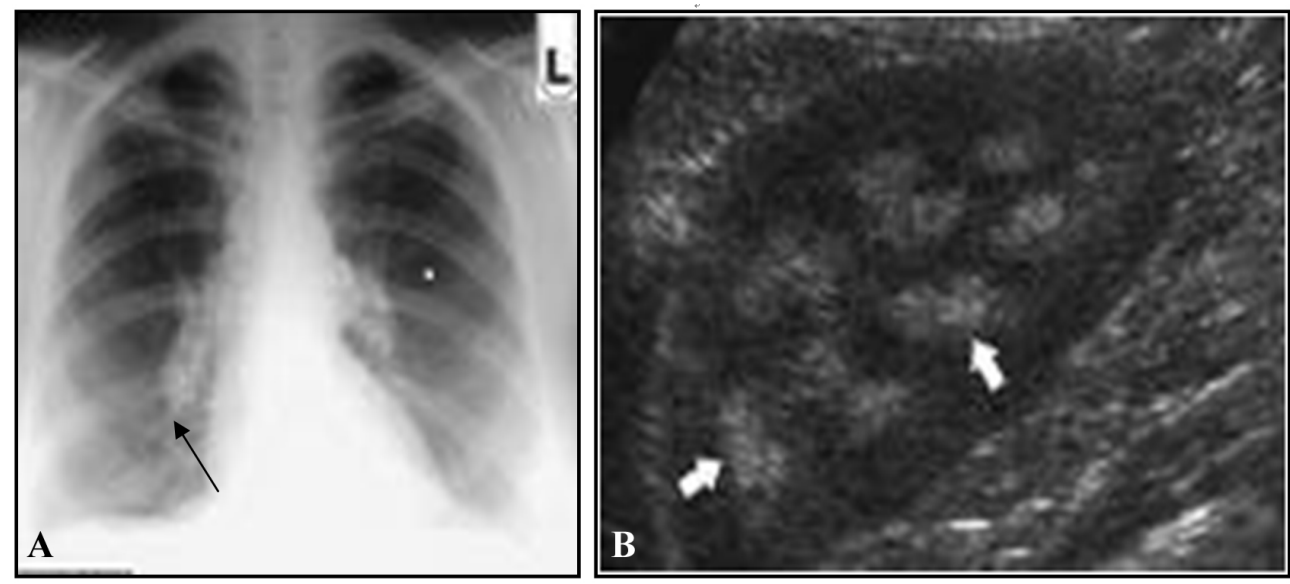

Figure 1. A: Chest X-Ray showing mild infiltrates (Black Arrow); B: Renal ultrasound with nephrocalcinosis (White Arrow) 


\subsection{Final diagnosis}

Closed kidney biopsy was performed revealed non caseating granulomas, consistent with sarcoidosis (see Figure 2).
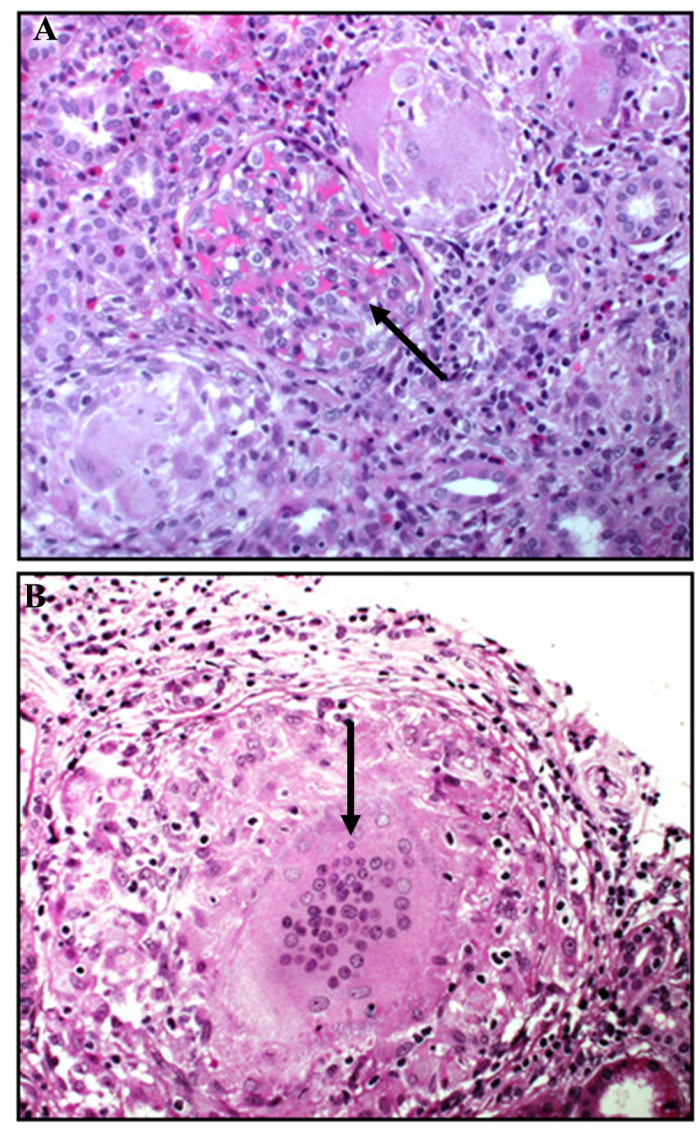

Figure 2. A: Renal biopsy demonstrating non-caseating granulomas with giant cells and interstitial lymphocytes (Black Arrows); B: Hematoxylin and eosin (HE) stain $400 \times$

\subsection{Hospital course}

The patient was treated with Prednisone $1 \mathrm{mg} / \mathrm{kg}$ for 12 weeks. Constitutional symptoms such as weakness and loss of appetite resolved completely, pulmonary function improved creatinine level declined to $1.01 \mathrm{mg} / \mathrm{dl}$, with normal blood calcium concentration. Prednisone was tapered and discontinued without any signs of relapse.

\section{Discussion}

Sarcoidosis is a systemic disease of unknown cause that is characterized by the formation of immune granulomas in various organs, mainly the lungs and the lymphatic system in more than $90 \%$ of patients. ${ }^{[1,7]}$ The real incidence and prevalence of renal involvement is difficult to establish, due to disease variablity; in most cases, it has been found in $35 \%$ to $50 \%$ of patients. Renal failure prevelance range from $0.7 \%$ to $4.3 \%$ of cases in previous reported clinical series of patients with sarcoidosis but renal failure from granulomatous interstitial nephritis induced nephropathy itself is rare. ${ }^{[6-8]}$

A previous study found that 46 of $9,779(0.5 \%)$ renal biopsy specimens had granulomatous interstitial nephritis. The pathology contributing to acute kidney injury from GIN in sarcoidosis is thought to be due to noncaseating granulomatous inflammation, which is composed of a central follicle of macrophages, epithelioid cells, and multinucleated giant cells. Hypercalcemia, a well-known metabolic complication of sarcoidosis, is only found in $10 \%-20 \%$ of patients and can directly cause acute kidney injury. Hypercalcemia as in our young patient, is due to overproduction of 1,25-dihydroxy vitamin D. In patients with sarcoidosis, hypercalciuria is three times more common than hypercalcemia with a frequency in some studies as high as $60 \%$. Both can lead to acute and chronic kidney injury in sarcoidosis by causing nephrolithiasis and nephrocalcinosis. Hypercalcemia and hypercalciuria contribute to the formation of calcium oxalate crystals which can be the cause of nephrolithiasis. Our case demonstrates that renal granulomatous interstitial nephritis related to sarcoidosis, although a rare entity can cause severe acute kidney injury and progressive renal failure unless promptly diagnosed and treated. ${ }^{[9,10]}$ Our patient was treated with steroids for 12 weeks. Constitutional symptoms resolved completely, pulmonary function improved. Plasma creatinine level decreased to $1.01 \mathrm{mg} / \mathrm{dl}$, with complete improvement of his symptoms. ${ }^{[11,20-22]}$

In conclusion, sarcoidosis is a disease involving multiple different organs including the kidney. Acute kidney injury as the initial presentation of sarcoidosis as was seen in our case is a rare entity. It is necessary to combine clinical presentation, laboratory results, and renal pathology to make a correct diagnosis which often responds well to treatment with steroids, ${ }^{[11,22]}$

\section{CONFlicts OF INTEREST Disclosure}

The authors have declared no conflicts of interest.

\section{REFERENCES}

[1] Coutant R, Leroy B, Niaudet P, et al. Renal granulomatous sarcoidosis in childhood: a report of 11 cases and a review of the literature. Eur J Pediatr. 1999; 158: 154-9. PMid:10048615 https : //doi.org/10.1007/s004310051038

[2] Palmucci S, Emanuele S, Daniele T, et al. Clinical and radiological features of extra-pulmonary sarcoidosis: a pictorial essay. Insights Imaging. 2016; 7(4): 571-587. PMid:27222055 https: 
//doi.org/10.1007/s13244-016-0495-4

[3] Ahmed MM, Mubashir E, Dossabhoy NR. Isolated renal sarcoidosis: a rare presentation of a rare disease treated with infliximab. Clin Rheumatol. 2007; 26(8): 1346-9. PMid:16850114 https: //doi.org/10.1007/s10067-006-0357-4

[4] Mahfoudi M, Mamlouk H, Turki S, et al. Systemic sarcoidosis complicated of acute renal failure: about 12 cases. Africa Medical Journal. 2015.

[5] Rema J, Carvalho M, Vaz R, et al. Acute renal failure as a form of presentation of sarcoidosis in a young adult: a case report. $\mathrm{J}$ Med Case Rep. 2014; 8: 274. PMid:25124289 https ://doi .org/10.1 186/1752-1947-8-274

[6] Agrawal V, Crisi GM, D’Agati VD, et al. Renal sarcoidosis presenting as acute kidney injury with granulomatous interstitial nephritis and vasculitis. Am J Kidney Dis. 2012; 59(2): 303-8. PMid:22177616 https://doi.org/10.1053/j.ajkd.2011.09.025

[7] Shah S, Carter-Monroe N, Atta MG. Granulomatous interstitial nephritis. Clin Kidney J. 2015; 8(5): 516-523. PMid:26413275 https://doi.org/10.1093/ckj/sfv053

[8] Hishida E, Masuda T, Akimoto T, et al. Renal Failure Found during the Follow-up of Sarcoidosis: The Relevance of a Delay in the Diagnosis of Concurrent Hypercalcemia. Intern Med. 2016; 55(14): 1893-8. PMid:27432099

[9] Yadava M, Bala R. Electrophysiological correlates of cardiac sarcoidosis: an appraisal current evidence. Turk Kardiyol Dern Ars. 2015; 43(4): 392-401.

[10] Kefi A, Abdelhafidh NB, Sayhi S, et al. Sarcoidosis with heart involvement: a rare association of terrible prognosis, a report of two cases. Pan African Medical Journal. 2015; 21(1). https : //doi.org/10.11604/pamj . 2015.21.243.6124

[11] Saba R, Khreis M, Francisque F, et al. Rare case of sarcoidosis presenting with pancytopenia, acute renal failure and hypercalcaemia. BMJ Case Rep. 2016.

[12] Sharmeen S, Kalkan E, Yi C, et al. Granulomatous Interstitial Nephritis Presenting as Hypercalcemia and Nephrolithiasis. Case Rep
Nephrol. 2016; 2016(3): 1-6. PMid:26904327 https://doi.or g/10.1155/2016/4186086

[13] Miyoshi Ki, Okura T, Manabe S, et al. Granulomatous interstitial nephritis due to isolated renal sarcoidosis. Journal of Clinical and Experimental Nephrology. 2004; 8(3): 279-282. PMid:15480909 https ://doi.org/10.1007/s10157-004-0294-y

[14] Norman AW, Henry HL. Handbook of Vitamins, Vitamin D. Fourth Edition. Chapter 2.

[15] Mahévas M, Lescure FX, Boffa JJ, et al. Renal sarcoidosis: clinical, laboratory, and histological presentation and outcome in 47 patients. Medicine (Baltimore). 2009; 88(2): 98-106. PMid:19282700 https://doi.org/10.1097/MD.0b013e31819de50f

[16] Hilderson I, Van Laecke S, Wauters A, et al. Treatment of renal sarcoidosis: is there a guideline? Overview of the different treatment options. Nephrol Dial Transplant. 2014; 29(10): 1841-7. PMid:24235078 https : //doi.org/10.1093/ndt/gft442

[17] Moudgil A, Przygodzki RM, Kher KK. Successful steroid-sparing treatment of renal limited sarcoidosis with mycophenolate mofetil. 2006; 21(2): 281-285.

[18] Kouranos V, Jacob J, Wells AU. Severe Sarcoidosis. Clin Chest Med. 2015; 36(4): 715-26. PMid:26593144 https ://doi .org/10.101 6/j.ccm.2015.08.012

[19] Shetty AK, Gedalia A. Childhood sarcoidosis: A rare but fascinating disorder. Pediatric Rheumatol Online J. 2008; 6: 16-20. PMid:18811966 https://doi.org/10.1186/1546-0096-6-16

[20] Kempisty A, Kus J. Hypercalcemia and renal failure in the course of sarcoidosis-case report. Pneumonol Alergol Pol. 2012; 80(6): 570-5. PMid:23109211

[21] Nagaraja P, Davies MR. Granulomatous interstitial nephritis causing acute renal failure: a rare presenting feature of sarcoidosis. QJM 2014; 107(6): 467-9. PMid:22198941 https://doi.org/10.109 $3 /$ qjmed/hcr263

[22] Löffler U, Tuleweit A, Waldherr R, et al. Renal sarcoidosis: epidemiological and follow-up data in a cohort of 27 patients. Sarcoidosis Vasc Diffuse Lung Diis. 2015; 31(4): 306. 